\title{
Does motor lateralization have implications for stroke rehabilitation?
}

\author{
Robert L. Sainburg, PhD, MS, OTR; ${ }^{1-3^{*}}$ Susan V. Duff, OTR/L, PT, EdD ${ }^{1}$ \\ Departments of ${ }^{1}$ Kinesiology, ${ }^{2}$ Neuroscience, and ${ }^{3}$ Bioengineering, The Pennsylvania State University, University \\ Park, PA
}

\begin{abstract}
Recent findings on motor lateralization have revealed consistent differences in the control strategies of the dominant and nondominant hemisphere/limb systems that could have implications for hemiplegic stroke patients. Studies in stroke patients have demonstrated deficiencies in the ipsilesional arm that reflect these distinctions; patients with right-hemisphere damage tend to show deficits in positional accuracy, and patients with left-hemisphere damage show deficits in trajectory control. Such deficits have been shown to impede functional performance; yet patients with severe dominant-side hemiplegia must often use the nondominant arm as the primary manipulator for activities of daily living. Nevertheless, the nondominant arm may not spontaneously become efficient as a dominant manipulator, as indicated by the persistence of deficits in chronic stroke patients. More research is necessary to determine whether motor therapy can facilitate a more effective transition of this arm from a nondominant to a dominant controller.
\end{abstract}

Key words: coordination, dynamic dominance, handedness, hemiplegia, ipsilesional deficits, lateralization, motor control, motor learning, rehabilitation, stroke.

\section{INTRODUCTION}

Recent studies examining the neural foundations of motor lateralization are converging to provide a more thorough understanding of the neural and behavioral asymmetries that give rise to handedness. The dynamic dominance hypothesis describes specialization for control of limb trajectory and steady-state position, two distinct but complementary functions [1]. This division of labor is consistent with typical patterns of arm use during bimanual tasks, such as cutting bread or hammering nails, when the nondominant arm tends to stabilize an object against loads imposed by the dominant arm. In fact, Healey et al. described similar distinctions in dominant and nondominant arm use for a wide range of tasks across a large number of subjects [2]. The dynamic dominance model has recently been supported in studies of righthanded stroke patients that reveal deficits in the ipsilesional arm, the quality of which tend to vary with the side of the lesion [3-17]. The ipsilesional arm of these patients tends to show deficits in trajectory control following lefthemisphere damage and positional control following righthemisphere damage.

While earlier research emphasized the role of the contralateral hemisphere in controlling limb movements, more recent physiological and lesion studies have demonstrated a significant role of the ipsilateral hemisphere. In fact, both animal studies [18-20] and human studies [317] have revealed that unilateral brain damage can produce significant ipsilesional motor deficits. Studies in chronic stroke patients have reported performance deficiencies on the Purdue Pegboard Test [21], the JebsenTaylor Hand Function Test [22], as well as other tests that simulate activities of daily living (ADL) [4,10,13-14]. In

\footnotetext{
Abbreviations: ADL $=$ activities of daily living, $\mathrm{CIT}=$ constraint-induced therapy, EMG = electromyographic.

* Address all correspondence to Robert L. Sainburg, 29 REC Building, The Pennsylvania State University, University Park, PA 16802; 814-865-7938; fax: 814-863-4755. Email: rls45@psu.edu

DOI: 10.1682/JRRD.2005.01.0013
} 
addition, significant ipsilesional deficits in movement coordination and accuracy have been revealed with the use of motion capture systems [3,10-12,15,17]. Some studies that measured functional deficits have shown symmetric patterns that do not vary with lesion side $[4,14,17]$. However, Wetter et al. have recently shown that while deficiencies in functional performance tests can be similar for patients with right- and left-hemisphere damage, this pattern can result from differences in the underlying dysfunction [14]. For example, performance on a task, such as the simulated feeding task on the JebsenTaylor Hand Function Test, might be impaired by deficits in velocity control for left-hemisphere lesions and in accuracy control for right-hemisphere lesions. So, while the neural mechanisms underlying a particular dysfunction might be asymmetric, the scores on functional performance evaluations might be similar for right- and lefthemisphere lesions. Nevertheless, the occurrence of ipsilesional motor deficits following unilateral brain damage supports a role of both hemispheres in control of unilateral arm movements and has implications for functional performance.

Because ipsilesional deficits are usually mild compared with the contralesional hemiplegia that is often associated with stroke, these deficits traditionally have not been addressed in clinical rehabilitation. In fact, recent advances in therapeutic interventions for the contralesional arm have been very promising. Both robotaided rehabilitation [23-26] and constraint-induced movement therapy [27-30] have shown great promise for advancing function of the contralesional limbs. Constraint-induced therapy (CIT) is based on the idea that patients learn to "not use" the affected limb during the first few months following a stroke. This pattern of nonuse becomes habitual and contributes to a debilitating cycle of reduced use and function. CIT encourages the use of the affected limb for certain periods of time and for certain prescribed tasks and thus acts to reverse this cycle. CIT has been shown to improve both the quality of motor coordination as well as the functional use of the affected limb [27-30]. However, studies of CIT have tended to focus on patients who have significant active movement of the wrist and fingers. While a large number of rehabilitation patients may not qualify for CIT based on this requirement [31], recent research has suggested that more severely involved patients might show some benefits from CIT [27]. Robot-aided rehabilitation is another promising approach to remediation of the con- tralesional limbs. This technique uses robotic manipulanda to assist patients with voluntary active movement exercise and has been shown to produce substantial gains in active range of motion and strength. However, whether these improvements benefit functional living skills remains controversial $[23,26]$. The effectiveness of these developing techniques emphasizes the importance of aggressive rehabilitation directed toward remediation of motor function in the contralesional limb.

Regardless of gains in motor performance with the affected limb, many patients who suffer unilateral stroke will show persistent contralesional deficits that limit the function of this arm [31-34]. As a result, patients with moderate-to-severe hemiplegia must often use the ipsilesional arm to perform tasks unilaterally that were previously performed bilaterally [35]. Such tasks might include cutting food, using scissors, donning and doffing clothing, and performing personal hygiene tasks, among many others. Even though adapted equipment can help with these tasks, completing such activities with diminished contralateral coordination is likely to be challenging. For patients with substantial dominant-arm hemiplegia, performance of ADL relies largely on the arm that has been functioning as a nondominant controller throughout the individual's life. However, the persistence of ipsilesional deficits suggests that this arm does not spontaneously develop the efficiency of a dominant system simply through practice of ADL alone.

Deficits in the ipsilesional arm of stroke patients appear to be quite persistent, identified up to 15 years poststroke $[3,10-12,15,17]$. We now suggest that functional performance of a nondominant ipsilesional arm might be enhanced through therapy directed at retraining arm dominance. Current findings in motor lateralization research have provided substantial new insights into the basic functions that might need to be improved for more effective use of the nondominant limb as a dominant controller. However, this idea must be addressed with caution because we do not yet know whether a nondominant arm can be effectively retrained as a dominant controller. This article primarily describes current findings in motor lateralization that provide a basis for assessing the usefulness of dominance retraining strategies in patients with dominant-arm hemiplegia. 


\section{BIOLOGICAL FOUNDATIONS OF MOTOR LATERALIZATION}

Certain landmark studies have established that while trunk and limb girdle muscles are controlled through bilateral projections, control of arm musculature for reach and prehension arises primarily from descending projections originating in the contralateral cortex and brain stem [36-44]. However, subsequent electrophysiological and neural imaging studies have shown substantial activation of the ipsilateral motor cortex during unilateral hand and arm movements, indicating a role of both hemispheres in controlling each limb [45-62]. Many of these reports also indicate that the contributions of the left and right hemispheres are not symmetric. Rather, the hemisphere contralateral to the dominant arm tends to reflect higher levels of activity than its nondominant counterpart when unilateral movements of left and right arms are compared [47,53,61]. Morphological asymmetries have also been identified in the motor cortex [63], basal ganglia [64], and cerebellum [65]. In summary, while the contralateral hemisphere is most active during unilateral arm movements, the ipsilateral hemisphere is also substantially active. The functional activation of this hemisphere, however, is greater during nondominant than dominant arm movements, a finding that corresponds to anatomical asymmetries [45-62].

In light of substantial morphological and functional asymmetries, many studies have supported the premise that handedness is facilitated by genetic factors [66-69]. Annett's right-shift theory suggests a specific genetic determinant for only right-handedness [66]. Subjects without this genotype are not biased toward right-handedness, and thus most non-right-handers will not show strong hand preference in either direction. In support of this idea, Klar recently showed that right-handedness but not left-handedness correlates with hair whorl orientation, a trait unaffected by the environment [67]. In addition, patterns of hair whorl orientation and handedness in the offspring of monozygotic twins can be well predicted with a single gene model [67]. Whereas the nature-nurture debate regarding handedness remains controversial, substantial evidence now suggests that genetic factors contribute to the expression of handedness.

\section{LATERALIZATION OF MOTOR CONTROL PROCESSES}

Although asymmetries in neural structure and function verify the biological foundations of handedness, the neural processes mediated by these asymmetries remain incompletely understood. The largest body of research in this area has quantified reaction time, movement time, and final position accuracy during rapid reaching movements to differentiate "closed-loop" from "open-loop" mechanisms of control. Closed-loop mechanisms are, by definition, mediated by sensory feedback during the course of movement, whereas open-loop mechanisms are unaffected by feedback. This distinction was inspired by Woodworth [70] and experimentally operationalized by Fitts and Radford [71-73]. Attempts to differentiate the role of sensory feedback on dominant and nondominant arm movements have been largely equivocal. Flowers [74] and others [75-80] have suggested that manual asymmetries emerge from differences in the use of visual feedback that arise when the precision requirements of aiming tasks become high as reflected by the task's index of difficulty [81]. However, studies that failed to find interlimb differences in accuracy by manipulating visual feedback conditions brought this hypothesis into question [75,82-84]. Demonstrating that dominant-arm advantages do not depend on visual feedback conditions, Carson et al. suggested that such advantages result from more effective somatosensory-based error corrections [85]. However, we recently showed that it is the nondominant arm that shows substantial advantages in compensating for unexpected loads using somatosensory information [86-87]. In that study, subjects made rapid elbow extension movements toward a single target. On some trials, a $1 \mathrm{~kg}$ mass was attached to an arm splint. Both arms showed compensatory muscle activity in response to the load in the first $100 \mathrm{~ms}$ of movement, reflecting the latencies of short-loop somatosensory feedback circuits. Interestingly, nondominant responses were more effective at reducing error than dominant responses, indicating a nondominant-arm advantage for somatsensory-based error corrections [86-87].

In contrast to feedback mechanisms, some studies have proposed a dominant-arm or -hemisphere advantage for movement planning, initiation, or sequencing [8891]. However, studies demonstrating nondominant-arm advantages for reaction time [92-93] have proposed a nondominant specialization for movement preparation. 
Taken together, this body of research has been largely unsuccessful in resolving the processes that underlie motor lateralization. This leaves open the question of how else one might understand the neural basis of handedness $[83,94]$.

\section{DYNAMIC DOMINANCE}

We have recently provided substantial evidence that each hemisphere or limb system is specialized for distinct but complementary functions: the dominant system for controlling limb trajectory and the nondominant system for controlling stable limb posture $[1,94]$. We termed this hypothesis "dynamic dominance" because of evidence that dominant-arm trajectory control entails more efficient and accurate coordination of muscle actions with the complex biomechanical interactions that arise between the moving segments of the limb. Prominent among these are interaction torques, produced when the end of one segment pushes on the end of the other segment through the joint connecting the two. For example, one can hold the right upper arm with the left hand and move the arm back and forth. If one relaxes the muscles about the right elbow, the forearm will "flop" back and forth. The torque that produces this motion is referred to as an interaction torque. For any given segment, motion of attached segments will impose interaction torques that vary with the velocities and accelerations of those segments and that also vary with the instantaneous configuration of the limb. During limb movements, these interactions produce large torques that often exceed the amplitude of muscle actions on the segments [95-98]. The nervous system must account for these interactions to coordinate the segments of the arm during movements such as reaching.

\section{Dominant Specialization for Control of Intersegmental Dynamics}

To test whether the dominant and nondominant limbs coordinate the motion of multiple segments differently, we designed a reaching task that would elicit progressively greater interaction torques at the elbow joint [99-100]. The general experimental setup for these experiments is shown in Figure 1(a). The subject's arm was supported on a frictionless air-sled support while he or she viewed a virtual-reality environment projected above the arm. After aligning the hand within a start circle, the subject made

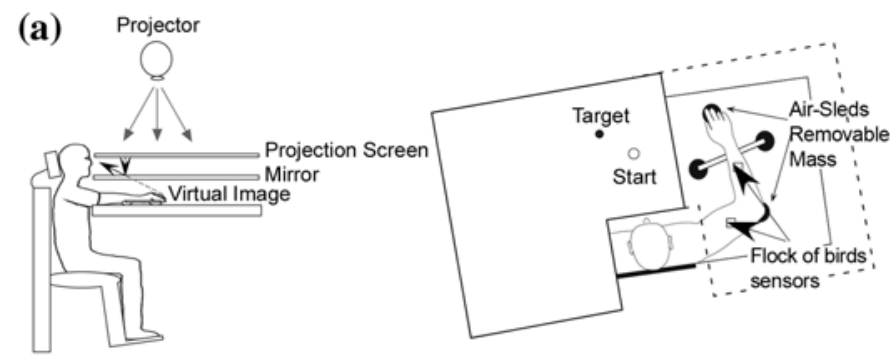

(b)

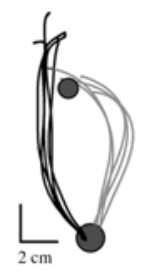

Target 3

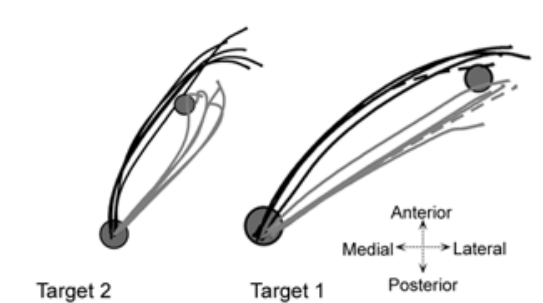

(c)
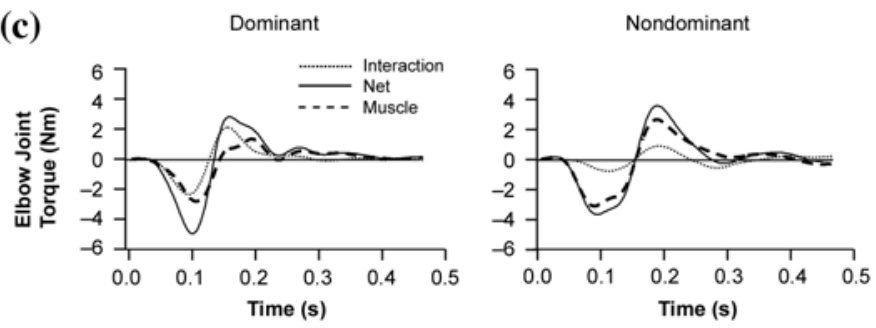

Figure 1.

(a) Experimental setup. Side view (left), top view (right). Subjects sit facing a table, with arm supported on an air-sled. Targets and cursor representing finger position is projected onto a back-projection screen placed above eye level. A mirror, placed under this, reflects projection and provides a virtual task plane that appears to be at level of hand. Flock of birds, 6 degree of freedom sensors are attached to each limb segment. (b) Hand paths for nondominant (left arm: gray) and dominant (right arm: black) movements. Paths are presented in a right-hand coordinate system, such that dominant arm movements are presented in actual coordinates, whereas for nondominant arm, $x$-axis has been reversed. (c) Elbow joint torques for dominant and nondominant arm movements, depicted as dashed lines in Figure 1(b) (right side).

rapid reaching movements to projected target positions. All three targets required the same elbow excursion $\left(20^{\circ}\right)$, but different shoulder excursions (target $1,5^{\circ}$; target 2 , $10^{\circ}$; and target $3,15^{\circ}$ ). As shown in the sample trajectories of Figure 1(b), final position accuracies were similar for both arms, yet slightly more accurate for the nondominant arm. However, the hand trajectories and respective joint coordination patterns were systematically different. Dominant-hand paths showed slight curvatures for all target directions, while those of the nondominant arm showed oppositely directed curvatures that increased in magnitude 
across directions (note that the hand paths of Figure 1(b) are presented in a right-hand coordinate system for both arms). Analysis of limb-segment torques revealed substantial differences in coordination such that dominantarm trajectories reflected more efficient strategy. This coordination is illustrated in Figure 1(c), which shows the dominant- and nondominant- arm elbow torques that correspond to the dashed trials for target 1 in Figure 1(b). Because the dominant arm employed greater shoulder motion (not shown), the elbow interaction torque was larger, such that smaller muscle torque (dashed line) was required to produce movements of the same speed and accuracy as those of the nondominant arm. Thus, the dominant-arm system consistently took advantage of intersegmental interactions to make movements that were more torque-efficient [1,94,97,100-101]. In fact, when the mean-squared muscle-torque at both joints for nondominant- and dominant-arm movements that were matched for speed and displacement, dominant-arm movements consistently required less than half the torque than that of nondominant movements. This emphasizes the fact that the coordination differences between the limbs are not simply a result of strength differences. In our tasks, nondominantarm movements demonstrate greater torque production, but less efficient movements. These findings have been corroborated by electromyographic (EMG) recordings, which revealed corresponding differences in normalized EMG activities between the limbs [99].

Because the dynamic dominance hypothesis proposes dominant system specialization for control of limb dynamics, it also predicts that features of control that do not stress intersegmental dynamics should not elicit asymmetries in performance. In a direct test of this prediction, we compared adaptation to an eccentrically positioned inertial load, which produced novel interaction torques, with adaptation to a rotated visual display (visual-motor rotation) that did not alter task dynamics [1]. As predicted by our hypothesis, the dominant arm showed more complete adaptation to the inertial load, whereas both limbs showed similar visual-motor adaptation. This confirmed that the advantages of the dominant system are specific to controlling limb dynamics.

\section{Interlimb Differences in Control of Movement Extent}

Reaching movements require both a trajectory phase, for accelerating the limb toward the target, and a postural phase, in which the limb decelerates and stops on or near the target. Because neural imaging studies have indicated that both the ipsilateral and contralateral cortices are activated during unimanual tasks, we expect that both systems may be used differentially in each phase of the task.

Because of the predominant activation of its contralateral cortex, one might expect that each arm would show a behavioral bias in the function for which its contralateral cortex appears specialized. We recently tested this hypothesis using a single-joint reaching task, which required rapid movements toward a range of targets. Figure 2 shows the (a) hand paths, (b) velocities, and (c) accelerations of the hand for a long and short target. Whereas both arms showed similar velocities and accuracies, our results indicated that the two limbs controlled movements through qualitatively different mechanisms [102]. For both arms, peak movement velocity scaled with movement distance, a phenomenon well described by previous literature [103-108]. Thus, the longer movement in Figure 2(a) had a peak velocity of about $1 \mathrm{~m} / \mathrm{s}$, whereas the shorter movement's peak velocity was about $0.4 \mathrm{~m} / \mathrm{s}$. However, the mechanisms employed by each limb to achieve this scaling were quite different. As can be seen by the acceleration plots of Figure 2(c) for the

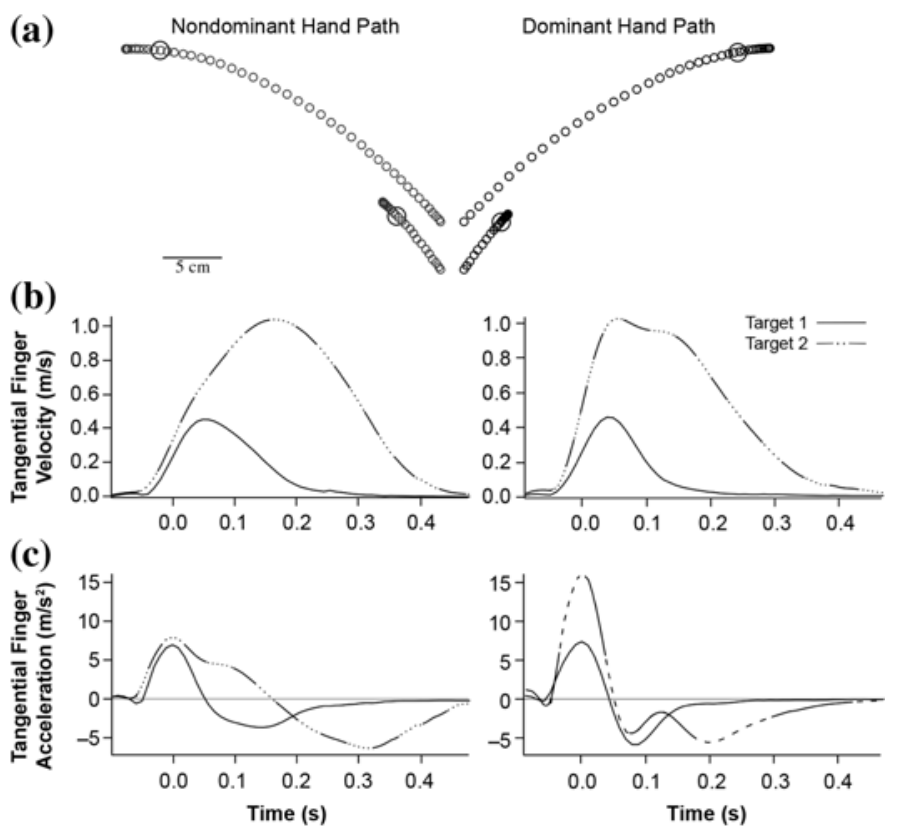

Figure 2.

Single-joint distance control task: (a) hand paths, (b) tangential velocity, and (c) tangential acceleration profiles. Data shown are ensemble averages of all trials for single subject and represent all subjects' performance. As described in text, experiment included four targets, but shortest and longest are shown here for demonstration. 
dominant arm, the initial amplitude of joint acceleration scaled with peak velocity, a predictive mechanism referred to as "pulse-height control" [103-116]. In contrast, the nondominant arm initiated each movement with a stereotypical acceleration amplitude, regardless of intended movement distance. Instead of varying acceleration with intended movement velocity, the nondominant system varied the duration of acceleration to accomplish the scaling of velocity with distance. This "pulse-width" mechanism has been associated with somatosensorybased modification mechanisms. In this case, such feedback apparently adjusted the duration of joint torque in accord with the intended final position [103,109114,116].

Thus, the dominant system appears to plan different velocities prior to movement onset, and the nondominant system uses online sensory feedback to adjust movement speed once the movement is already under way. This latter strategy may reflect a system that is more responsive to imposed forces such as those that might occur when stabilizing objects against loads imposed by dominantarm actions.

\section{Nondominant Specialization for Control of Limb Position}

Because few functional advantages in nondominantlimb performance have previously been identified, the nondominant system has traditionally been viewed as a naïve, unpracticed analog of the dominant-hemisphere or -limb system. In contrast to this view, recent findings from our laboratory have revealed substantial nondominant-limb advantages in positional accuracy [1,99-100], as well as in somatosensory-based load compensation responses [86-87]. Our findings suggest that the nondominant system is specialized for achieving and maintaining a stable limb position. This ability to stabilize is important not only for stopping at the end of a reaching movement but also for holding an object that is acted on by the dominant arm. For example, when slicing a loaf of bread, the dominant arm tends to control the knife that produces shearing forces on the bread. The nondominant arm impedes these forces to hold the bread still. Maintaining a stable posture in the face of varying forces requires active motor output that is specifically adapted to the imposed loads. Our dynamic dominance hypothesis suggests that the impedance control functions of the nondominant limb represent specialized processes. This idea is consistent with anthropological data that indicates that the specialized use of the "nondominant" arm for stabilizing objects evolved to support tool-making functions in early homonids [101,117].

After patients sustain a stroke that results in moderateto-severe hemiparesis of the dominant arm, the ipsilesional nondominant arm most likely will need to assume the function of a dominant controller in carrying out many ADL tasks. That is, this limb will serve as the lead manipulator in bilateral tasks and, in many cases, as the sole manipulator during unimanual tasks [31-35]. However, evidence for ipsilesional coordination deficits in unilateral stroke suggests that a patient's transition from nondominant to dominant controller does not occur spontaneously and might benefit from therapeutic intervention.

\section{EFFECT OF MOTOR LATERALIZATION IN UNI- LATERAL STROKE: IPSILESIONAL DEFICITS}

This research has direct and important implications for understanding the motor deficits resulting from unilateral stroke. Specifically, damage to the left or right hemisphere results in distinct deficits that depend on the side of the lesion. Most interesting is the prediction that damage to either the dominant or nondominant hemisphere should produce deficits in control of the ipsilesional limb. Studies in animals [18-20] as well as in patients with unilateral brain damage [3-17] have provided strong support to this idea. Haaland et al. have used perceptual motor tasks, which require rapid reciprocal tapping between two targets that vary in size and/or target distance, to examine movement deficits in the ipsilesional arm of stroke patients [5-9,118-119]. These experiments have employed horizontal movement in the ipsilesional hemispace with the ipsilesional arm (e.g., right hemispace and arm for patients with right-hemisphere damage) to rule out the confounding effects of motor weakness, visual field cuts, and visual neglect. Lesions in the dominant hemisphere (hemisphere contralateral to the dominant arm) produced deficits in the initial ballistic component of reaching but not in the secondary slower component [5-9,118-119]. Patients with nondominanthemisphere lesions showed no deficits in this task. However, in other studies with greater precision requirements, patients with nondominant lesions showed deficits in final position accuracy [5-9,15,118-119]. These results support the idea that the dominant hemisphere is specialized for controlling the initial trajectory phase of motion, 
whereas the nondominant hemisphere is more important in decelerating toward a stable posture.

Consistent with the those findings, Winstein and Pohl showed that nondominant lesions produced slowing of the deceleration phase of rapid aiming movements and dominant lesions produced slowing of the initial acceleration phase of motion [15]. In a more recent study, Haaland et al. directly tested the idea that dominant hemisphere lesions produce trajectory deficits and nondominant lesions produce deficits in the final position of targeted reaching movements [10]. In that study, righthanded patients with left-hemisphere lesions showed distinct deficits in movement speed, whereas patients with right-hemisphere lesions showed substantial final position errors when compared with age-matched control subjects. These authors concluded that their findings are most consistent with our dynamic dominance model of motor lateralization. Such ipsilesional deficits have been associated with substantially impaired performance on functional assessments, including simulated ADL [4,13$14]$, and also have been shown to produce deficits in interjoint coordination [17].

\section{CONCLUSIONS: IMPLICATIONS OF MOTOR LATERALIZATION FOR STROKE REHABILITATION}

When stroke patients have moderate-to-severe hemiplegia, the contralesional arm will not likely be used spontaneously as the lead arm in bimanual activities, such as unscrewing a jar lid, fastening buttons, or slicing food, or as the dominant controller in unilateral activities, such as transporting a cup of coffee to the mouth. In fact, longitudinal studies have estimated that a minority of hemiplegic stroke patients will demonstrate full functional recovery in the contralesional limbs [31-35]. Bonifer et al. reported that even after engaging in a CIT trial that improved active movement, the contralesional arm of moderately impaired patients continued to be used to assist with bimanual activities, rather than as the lead controller in unimanual and bimanual tasks [27-28]. Vega-Gonzalez and Granat continuously monitored spontaneous use of both arms in chronic stroke patients and reported that hemiplegic patients used the ipsilesional limb three to six times more frequently than its hemiparetic counterpart [33]. In some of these patients, reliance on the ipsilesional limb might plausibly be due to learned nonuse. However, in many cases such reliance is due to persistent contralesional motor deficits [31]. Thus, for many hemiplegic patients, functional recovery relies heavily on ipsilesional limb function. This reliance is why occupational therapy has so often employed "compensatory" training in the ipsilesional limb to regain independence in ADL [35].

We now propose that the requirement to switch the function of the previously nondominant limb to a dominant controller might be impeded by ipsilesional motor deficits and might be enhanced through remedial therapy. We stress that the degree to which hand dominance can be "retrained" in such patients is currently unknown. Therefore, experimentally examining whether such training could improve ipslesional function appears necessary. With training, subjects could likely gain greater "dominant” functionality from the ipsilesional limb, regardless of whether it was the preferred limb prior to the stroke. While it is common for therapists to train ADL through repetition until the patient becomes somewhat independent in these tasks, the persistence of ipsilesional deficits supports the idea that such compensatory training does not lead to generalized improvements in motor proficiency.

We now suggest that using techniques such as engaging in supervised activities that require dominant control functions (making rapid targeted movements, tracing paths that elicit large intersegmental forces) and adapting to novel dynamic conditions might facilitate more efficient coordination in the "nondominant" ipsilesional arm of chronic hemiplegic patients. Such training could take advantage of recent technological advances, such as robot-assisted therapy [23-26]. Currently, this technique employs robotic manipulanda to provide active assistance to reaching movements of the contralesional limb. Robot-assisted interventions could plausibly be expanded to challenge the trajectory control functions of the ipsilesional nondominant limb. Patients could be required to make rapid targeted movements against varied loads to train control of intersegmental coordination. Predictable but varied loads could be imposed to train the ability to specify a range of joint torques during movements. In a similar way, robotic devices could be employed to challenge and train the stability functions of the contralesional limb while it is positioned in a variety of workspace locations.

We must stress that these therapeutic interventions are purely hypothetical. More research is necessary to determine the degree to which ipsilesional deficits limit 
functional performance in patients with dominant-arm hemiplegia and whether therapy can enhance coordination in this arm. While a number of studies to date have indicated a correlation between functional performance and ipsilesional deficits [4,13-14], whether these effects are most severe for patients with dominant arm hemiplegia is not yet known. Most importantly, whether dominance can be effectively retrained in such patients remains untested. Based on the research presented in this article, we hypothesize that patients with persistent dominant-arm hemiplegia could benefit from dominance retraining strategies directed at developing more efficient coordination in the ipsilesional arm.

\section{ACKNOWLEDGMENTS}

This material was based on work supported by the National Institutes of Health, National Institute for Child Health and Human Development (grant R01HD39311), the Center for Medical Rehabilitation Research, and the National Institute for Neural Disorders and Stroke National Research Service Award (grant F32-NS-46239).

The authors have declared that no competing interests exist.

\section{REFERENCES}

1. Sainburg RL. Evidence for a dynamic-dominance hypothesis of handedness. Exp Brain Res. 2003;142(2):241-58. [PMID: 11807578]

2. Healey JM, Liederman J, Geschwind N. Handedness is not a unidimensional trait. Cortex. 1986;22(1):33-53. [PMID: 3709192]

3. Carey JR, Baxter TL, Di Fabio RP. Tracking control in the nonparetic hand of subjects with stroke. Arch Phys Med Rehabil. 1998;79(4):435-41. [PMID: 9552111]

4. Desrosiers J, Bourbonnais D, Bravo G, Roy PM, Guay M. Performance of the 'unaffected' upper extremity of elderly stroke patients. Stroke. 1996;27(9):1564-70. [PMID: 8784131]

5. Haaland KY, Cleeland CS, Carr D. Motor performance after unilateral hemisphere damage in patients with tumor. Arch Neurol. 1977;34(9):556-59. [PMID: 889498$]$

6. Haaland KY, Delaney HD. Motor deficits after left or right hemisphere damage due to stroke or tumor. Neuropsychologia. 1981;19(1):17-27. [PMID: 6785661]
7. Haaland KY, Harrington D. The role of the hemispheres in closed loop movements. Brain Cogn. 1989;9(2):158-80. [PMID: 2923708]

8. Haaland KY, Harrington DL. Hemispheric asymmetry of movement. Curr Opin Neurobiol. 1996;6(6):796-800. [PMID: 9000021]

9. Haaland KY, Harrington DL. Hemispheric control of the initial and corrective components of aiming movements. Neuropsychologia. 1989;27(7):961-69. [PMID: 2771034]

10. Haaland KY, Prestopnik JL, Knight RT, Lee RR. Hemispheric asymmetries for kinematic and positional aspects of reaching. Brain. 2004;127(Pt 5):1145-58. [PMID: 15033898]

11. Harrington DL, Haaland KY. Hemispheric specialization for motor sequencing: Abnormalities in levels of programming. Neuropsychologia. 1991;29(2):147-63. [PMID: 2027431]

12. Schaefer SY, Sainburg RL, Haaland KY. Differential hemispheric contributions to unilateral arm movements [abstract]. Soc Neurosci. 2005;Program number 181.4.

13. Sunderland A. Recovery of ipsilateral dexterity after stroke. Stroke. 2000;31(2):430-33. [PMID: 10657418]

14. Wetter S, Poole JL, Haaland KY. Functional implications of ipsilesional motor deficits after unilateral stroke. Arch Phys Med Rehabil. 2005;86(4):776-81. [PMID: 15827931]

15. Winstein CJ, Pohl PS. Effects of unilateral brain damage on the control of goal-directed hand movements. Exp Brain Res. 1995;105(1):163-74. [PMID: 7589312]

16. Wyke M. Effect of brain lesions on the rapidity of arm movement. Neurology. 1967;17(11):1113-20. [PMID: 6069298]

17. Yarosh CA, Hoffman DS, Strick PL. Deficits in movements of the wrist ipsilateral to a stroke in hemiparetic subjects. J Neurophysiol. 2004;92(6):3276-85.

[PMID: 15295013]

18. Gonzalez CL, Gharbawie OA, Williams PT, Kleim JA, Kolb B, Whishaw IQ. Evidence for bilateral control of skilled movements: Ipsilateral skilled forelimb reaching deficits and functional recovery in rats follow motor cortex and lateral frontal cortex lesions. Eur J Neurosci. 2004;20(12):3442-52. [PMID: 15610177]

19. Grabowski M, Brundin P, Johansson BB. Paw-reaching, sensorimotor, and rotational behavior after brain infarction in rats. Stroke. 1993;24(6):889-95. [PMID: 8506561]

20. Vergara-Aragon P, Gonzalez CL, Whishaw IQ. A novel skilled-reaching impairment in paw supination on the "good" side of the hemi-Parkinson rat improved with rehabilitation. J Neurosci. 2003;23(2):579-86. [PMID: 12533618]

21. Rapin I, Tourk LM, Costa LD. Evaluation of the Purdue Pegboard as a screening test for brain damage. Dev Med Child Neurol. 1966;8(1):45-54. [PMID: 5922056] 
22. Jebsen RH, Taylor N, Trieschmann RB, Trotter MJ, Howard LA. An objective and standardized test of hand function. Arch Phys Med Rehabil. 1969;50(6):311-19. [PMID: 5788487]

23. Hidler J, Nichols D, Pelliccio M, Brady K. Advances in the understanding and treatment of stroke impairment using robotic devices. Top Stroke Rehabil. 2005;12(2): 22-35. [PMID: 15940582]

24. Volpe BT, Ferraro M, Krebs HI, Hogan N. Robotics in the rehabilitation treatment of patients with stroke. Curr Atheroscler Rep. 2002;4(4):270-76. [PMID: 12052277]

25. Volpe BT, Ferraro M, Lynch D, Christos P, Krol J, Trudell C, Krebs HI, Hogan N. Robotics and other devices in the treatment of patients recovering from stroke. Curr Atheroscler Rep. 2004;6(4):314-19.

[PMID: 15191707]

26. Volpe BT, Krebs HI, Hogan N. Robot-aided sensorimotor training in stroke rehabilitation. Adv Neurol. 2003;92: 429-33. [PMID: 12760210]

27. Bonifer NM, Anderson KM, Arciniegas DB. Constraintinduced movement therapy after stroke: Efficacy for patients with minimal upper-extremity motor ability. Arch Phys Med Rehabil. 2005;86(9):1867-73. [PMID: 16181956]

28. Bonifer NM, Anderson KM, Arciniegas DB. Constraintinduced therapy for moderate chronic upper extremity impairment after stroke. Brain Inj. 2005;19(5):323-30. [PMID: 16094779]

29. Mark VW, Taub E. Constraint-induced movement therapy for chronic stroke hemiparesis and other disabilities. Restor Neurol Neurosci. 2004;22(3-5):317-36. [PMID: 15502259]

30. Wolf SL, Thompson PA, Morris DM, Rose DK, Winstein CJ, Taub E, Giuliani C, Pearson SL. The EXCITE trial: Attributes of the Wolf Motor Function Test in patients with subacute stroke. Neurorehabil Neural Repair. 2005; 19(3):194-205. [PMID: 16093410]

31. Kwakkel G, Kollen BJ, Van der Grond J, Prevo AJ. Probability of regaining dexterity in the flaccid upper limb: Impact of severity of paresis and time since onset in acute stroke. Stroke. 2003;34(9):2181-86. [PMID: 12907818]

32. Parry RH, Lincoln NB, Vass CD. Effect of severity of arm impairment on response to additional physiotherapy early after stroke. Clin Rehabil. 1999;13(3):187-98. [PMID: 10392645]

33. Vega-Gonzalez A, Granat MH. Continuous monitoring of upper-limb activity in a free-living environment. Arch Phys Med Rehabil. 2005;86(3):541-48. [PMID: 15759242]

34. Wade DT, Langton-Hewer R, Wood VA, Skilbeck CE, Ismail HM. The hemiplegic arm after stroke: Measurement and recovery. J Neurol Neurosurg Psychiatry. 1983;46(6):521-24. [PMID: 6875585]
35. Sullivan JW, Ryan PA. Activities of daily living adaptations: Managing the environment with one-handed techniques. In: Gillen G, Burkhardt A, editors. Stroke rehabilitation: A function-based approach. St. Louis (MO): Mosby; 2005. p. 479-95.

36. Holstege G, Kuypers HG. The anatomy of brain stem pathways to the spinal cord in cat. A labeled amino acid tracing study. Prog Brain Res. 1982;57:145-75.

[PMID: 7156396]

37. Holstege JC, Kuypers HG. Brainstem projections to lumbar motoneurons in rat-I. An ultrastructural study using autoradiography and the combination of autoradiography and horseradish peroxidase histochemistry. Neuroscience. 1987;21(2):345-67. [PMID: 3614638]

38. Kuypers HG. A new look at the organization of the motor system. Prog Brain Res. 1982;57:381-403.

[PMID: 6818612]

39. Kuypers HG, Brinkman J. Precentral projections to different parts of the spinal intermediate zone in the rhesus monkey. Brain Res. 1970;24(1):29-48. [PMID: 4099987]

40. Kuypers HG, Laurence DG. Cortical projections to the red nucleus and the brain stem in the rhesus monkey. Brain Res. 1967;4(2):151-88. [PMID: 4961812]

41. Kuypers HG, Fleming WR, Farinholt JW. Subcorticospinal projections in the rhesus monkey. J Comp Neurol. 1962;118:107-37. [PMID: 14461005]

42. Kuypers HG, Maisky VA. Retrograde axonal transport of horseradish peroxidase from spinal cord to brain stem cell groups in the cat. Neurosci Lett. 1975;1:9-14.

43. Lawrence DG, Kuypers HG. The functional organization of the motor system in the monkey. I. The effects of bilateral pyramidal lesions. Brain. 1968;91(1):1-14.

[PMID: 4966862]

44. Lawrence DG, Kuypers HG. The functional organization of the motor system in the monkey. II. The effects of lesions of the descending brain-stem pathways. Brain. 1968;91(1):15-36. [PMID: 4966860]

45. Chen R, Cohen LG, Hallett M. Role of the ipsilateral motor cortex in voluntary movement. Can J Neurol Sci. 1997;24(4):284-91. [PMID: 9398974]

46. Chen R, Gerloff C, Hallett M, Cohen LG. Involvement of the ipsilateral motor cortex in finger movements of different complexities. Ann Neurol. 1997;41(2):247-54. [PMID: 9209074]

47. Dassonville P, Zhu XH, Uurbil K, Kim SG, Ashe J. Functional activation in motor cortex reflects the direction and the degree of handedness. Proc Natl Acad Sci USA 1997;94(25):14015-18. [PMID: 9391144] Erratum in: Proc Natl Acad Sci USA. 1998;95(19):11499.

48. Gitelman DR, Alpert NM, Kosslyn S, Daffner K, Scinto L, Thompson W, Mesulam MM. Functional imaging of 
human right hemispheric activation for exploratory movements. Ann Neurol. 1996;39(2):174-79. [PMID: 8967748]

49. Kawashima R, Inoue K, Sato K, Fukuda H. Functional asymmetry of cortical motor control in left-handed subjects. Neuroreport. 1997;8(7):1729-32. [PMID: 9189922]

50. Kawashima R, Itoh H, Ono S, Satoh K, Furumoto S, Gotoh R, Koyama M, Yoshioka S, Takahashi T, Takahashi K, Yanagisawa T, Fukuda H. Changes in regional cerebral blood flow during self-paced arm and finger movements. A PET study. Brain Res. 1996;716(1-2):141-48.

[PMID: 8738230]

51. Kawashima R, Matsumura M, Sadato N, Naito E, Waki A, Nakamura S, Matsunami K, Fukuda H, Yonekura Y. Regional cerebral blood flow changes in human brain related to ipsilateral and contralateral complex hand movements—A PET study. Eur J Neurosci. 1998;10(7):2254-60. [PMID: 9749754]

52. Kawashima R, Roland PE, O’Sullivan BT. Activity in the human primary motor cortex related to ipsilateral hand movements. Brain Res. 1994;663(2):251-56.

[PMID: 7874508]

53. Kim SG, Ashe J, Hendrich K, Ellermann JM, Merkle H, Ugurbil K, Georgopoulos AP. Functional magnetic resonance imaging of motor cortex: Hemispheric asymmetry and handedness. Science. 1993;261(5121):615-17. [PMID: 8342027]

54. Kutas M, Donchin E. Studies of squeezing: Handedness, responding hand, response force, and asymmetry of readiness potential. Science. 1974;186(4163):545-48.

[PMID: 4469679]

55. Macdonell RA, Shapiro BE, Chiappa KH, Helmers SL, Cros D, Day BJ, Shahani BT. Hemispheric threshold differences for motor evoked potentials produced by magnetic coil stimulation. Neurology. 1991;41(9):1441-44. [PMID: 1891095]

56. Matsunami K, Hamada I. Characteristics of the ipsilateral movement-related neuron in the motor cortex of the monkey. Brain Res. 1981;204(1):29-42. [PMID: 7248755]

57. Salmelin R, Forss N, Knuutila J, Hari R. Bilateral activation of the human somatomotor cortex by distal hand movements. Electroencephalogr Clin Neurophysiol. 1995;95(6):444-52. [PMID: 8536573]

58. Taniguchi M, Yoshimine T, Cheyne D, Kato A, Kihara T, Ninomiya H, Hirata M, Hirabuki N, Nakamura H, Hayakawa T. Neuromagnetic fields preceding unilateral movements in dextrals and sinistrals. Neuroreport. 1998;9(7):1497-1502. [PMID: 9631455]

59. Tanji J, Okano K, Sato KC. Neuronal activity in cortical motor areas related to ipsilateral, contralateral, and bilateral digit movements of the monkey. J Neurophysiol. 1988; 60(1):325-43. [PMID: 3404223]
60. Urbano A, Babiloni C, Onorati P, Babiloni F. Human cortical activity related to unilateral movements. A high resolution EEG study. Neuroreport. 1996;8(1):203-6. [PMID: 9051781]

61. Viviani P, Perani D, Grassi F, Bettinardi V, Fazio F. Hemispheric asymmetries and bimanual asynchrony in left- and right-handers. Exp Brain Res. 1998;120(4):531-36. [PMID: 9655240]

62. Volkmann J, Schnitzler A, Witte OW, Freund H. Handedness and asymmetry of hand representation in human motor cortex. J Neurophysiol. 1998;79(4):2149-54. [PMID: 9535974]

63. Amunts K, Schlaug G, Schleicher A, Steinmetz H, Dabringhaus A, Roland PE, Zilles K. Asymmetry in the human motor cortex and handedness. Neuroimage. 1996; 4(3 Pt 1):216-22. [PMID: 9345512]

64. Kooistra CA, Heilman KM. Motor dominance and lateral asymmetry of the globus pallidus. Neurology. 1988;38(3): 388-90. [PMID: 3347342]

65. Snyder PJ, Bilder RM, Wu H, Bogerts B, Lieberman JA. Cerebellar volume asymmetries are related to handedness: A quantitative MRI study. Neuropsychologia. 1995;33(4): 407-19. [PMID: 7617152]

66. Annett M. Cerebral asymmetry in twins: Predictions of the right shift theory. Neuropsychologia. 2003;41(4):469-79. [PMID: 12559163]

67. Klar AJ. Human handedness and scalp hair-whorl direction develop from a common genetic mechanism. Genetics. 2003;165(1):269-76. [PMID: 14504234]

68. McManus IC. Right- and left-hand skill: Failure of the right shift model. Br J Psychol. 1985;76(Pt 1):1-34. [PMID: 3978353]

69. McManus IC. The inheritance of left-handedness. Ciba Found Symp. 1991;162:251-67; discussion 267-81. [PMID: 1839378]

70. Woodworth RS. The accuracy of voluntary movement. Psychol Monogr. 1899;3(2):1-114.

71. Fitts PM. Cognitive aspects of information processing. 3. Set for speed versus accuracy. J Exp Psychol. 1966;71(6): 849-57. [PMID: 5939364]

72. Fitts PM. The information capacity of the human motor system in controlling the amplitude of movement (1954). Reprinted in: J Exp Psychol Gen. 1992;121(3):262-69. [PMID: 1402698]

73. Fitts PM, Radford BK. Information capacity of discrete motor responses under different cognitive sets. J Exp Psychol. 1966;71(4):475-82. [PMID: 5909070]

74. Flowers K. Handedness and controlled movement. Br J Psychol. 1975;66(1):39-52. [PMID: 1131479]

75. Carson RG. Manual asymmetries: Old problems and new directions. Hum Mov Sci. 1993;12(5):479-506. 
76. Elliott D, Chua R, Pollock BJ. The influence of intermittent vision on manual aiming. Acta Psychol (Amst). 1994; 85(1):1-13. [PMID: 8165920]

77. Elliott D, Lyons J, Chua R, Goodman D, Carson RG. The influence of target perturbation on manual aiming asymmetries in right-handers. Cortex. 1995;31(4):685-97. [PMID: 8750026]

78. Roy EA, Kalbfleisch L, Elliott D. Kinematic analyses of manual asymmetries in visual aiming movements. Brain Cogn. 1994;24(2):289-95. [PMID: 8185899]

79. Todor JI, Cisneros J. Accommodation to increased accuracy demands by the right and left hands. J Mot Behav. 1985;17(3):355-72. [PMID: 15240687]

80. Todor JI, Doane T. Handedness classification: Preference versus proficiency. Percept Mot Skills. 1977;45(3 Pt 2): 1041-42. [PMID: 604877]

81. Plamondon R, Alimi AM. Speed/accuracy trade-offs in target-directed movements. Behav Brain Sci. 1997;20(2):279303; discussion 303-49. [PMID: 10096999]

82. Carson RG. Visual feedback processing and manual asymmetries: An evolving perspective. In: Proteau L, Elliott D, editors. Vision and motor control (Advances in psychology). Amsterdam (the Netherlands): North-Holland; 1992. p. 49-65.

83. Carson RG, Chua R, Elliott D, Goodman D. The contribution of vision to asymmetries in manual aiming. Neuropsychologia. 1990;28(11):1215-20. [PMID: 2290495]

84. Roy EA, Elliott D. Manual asymmetries in visually directed aiming. Can J Psychol. 1986;40(2):109-21. [PMID: 3730950]

85. Carson RG, Goodman D, Chua R, Elliott D. Asymmetries in the regulation of visually guided aiming. J Mot Behav. 1993;25(1):21-32. [PMID: 12730038]

86. Bagesteiro LB, Sainburg RL. Interlimb transfer of load compensation during rapid elbow joint movements. Exp Brain Res. 2005;161(2):155-65. [PMID: 15551087]

87. Bagesteiro LB, Sainburg RL. Nondominant arm advantages in load compensation during rapid elbow joint movements. J Neurophysiol. 2003;90(3):1503-13. [PMID: 12736237]

88. Annett J, Annett M, Hudson PT, Turner A. The control of movement in the preferred and non-preferred hands. Q J Exp Psychol. 1979;31:641-52. [PMID: 534286]

89. Carson RG, Chua R, Goodman D, Byblow WD, Elliott D. The preparation of aiming movements. Brain Cogn. 1995; 28(2):133-54. [PMID: 7546669]

90. Todor JI, Kyprie PM. Hand differences in the rate and variability of rapid tapping. J Mot Behav. 1980;12(1):57-62. [PMID: 15215068]

91. Todor JI, Smiley-Oyen AL. Force modulation as a source of hand differences in rapid finger tapping. Acta Psychol. 1987;65:65-73.
92. Elliott D, Roy EA, Goodman D, Carson RG. Asymmetries in the preparation and control of manual aiming movements. Can J Exp Psychol. 1993;47(3):570-89.

93. Mieschke PE, Elliott D, Helsen WF, Carson RG, Coull JA. Manual asymmetries in the preparation and control of goaldirected movements. Brain Cogn. 2001;45(1):129-40. [PMID: 11161367]

94. Sainburg RL. Handedness: Differential specializations for control of trajectory and position. Exerc Sport Sci Rev. 2005;33(4):206-13. [PMID: 16239839]

95. Ghez C, Sainburg R. Proprioceptive control of interjoint coordination. Can J Physiol Pharmacol. 1995;73(2):273-84. [PMID: 7621366]

96. Gribble PL, Ostry DJ. Compensation for interaction torques during single- and multijoint limb movement. J Neurophysiol. 1999;82(5):2310-26. [PMID: 10561408]

97. Sainburg RL, Ghez C, Kalakanis D. Intersegmental dynamics are controlled by sequential anticipatory, error correction, and postural mechanisms. J Neurophysiol. 1999;81(3):1040-56. [PMID: 10085332]

98. Sainburg RL, Ghilardi MF, Poizner H, Ghez C. Control of limb dynamics in normal subjects and patients without proprioception. J Neurophysiol. 1995;73(2):820-35. [PMID: 7760137]

99. Bagesteiro LB, Sainburg RL. Handedness: Dominant arm advantages in control of limb dynamics. J Neurophysiol. 2002;88(5):2408-21. [PMID: 12424282]

100. Sainburg RL, Kalakanis D. Differences in control of limb dynamics during dominant and nondominant arm reaching. J Neurophysiol. 2000;83(5):2661-75. [PMID: 10805666]

101. Sainburg RL, Eckhardt RB. Optimization through lateralization: The evolution of handedness. Behav Brain Sci. 2005;28:611-12.

102. Sainburg RL, Schaefer SY. Interlimb differences in control of movement extent. J Neurophysiol. 2004;92(3): 1374-83. [PMID: 15115793]

103. Ghez C, Hening W, Gordon J. Organization of voluntary movement. Curr Opin Neurobiol. 199;1(4):664-71. [PMID: 1822314]

104. Gordon J, Ghez C. Trajectory control in targeted force impulses. II. Pulse height control. Exp Brain Res. 1987; 67(2):241-52. [PMID: 3622687]

105. Gordon J, Ghez C. Trajectory control in targeted force impulses. III. Compensatory adjustments for initial errors. Exp Brain Res. 1987;67(2):253-69. [PMID: 3622688]

106. Gottlieb GL, Corcos DM, Agarwal GC. Organizing principles for single-joint movements. I. A speed-insensitive strategy. J Neurophysiol. 1989;62(2):342-57.

[PMID: 2769334]

107. Gottlieb GL, Corcos DM, Agarwal GC, Latash ML. Organizing principles for single joint movements. III. 
JRRD, Volume 43, Number 3, 2006

Speed-insensitive strategy as a default. J Neurophysiol. 1990; 63(3):625-36. [PMID: 2329365]

108. Gottlieb GL, Latash ML, Corcos DM, Liubinskas TJ, Agarwal GC. Organizing principles for single joint movements: V. Agonist-antagonist interactions. J Neurophysiol. 1992;67(6):1417-27. [PMID: 1629754]

109. Brown SH, Cooke JD. Initial agonist burst duration depends on movement amplitude. Exp Brain Res. 1984;55(3):523-27. [PMID: 6468556]

110. Brown SH, Cooke JD. Initial agonist burst is modified by perturbations preceding movement. Brain Res. 1986; 377(2):311-22. [PMID: 3730866]

111. Brown SH, Cooke JD. Movement-related phasic muscle activation. I. Relations with temporal profile of movement. J Neurophysiol. 1990;63(3):455-64.

[PMID: 2329355]

112. Brown SH, Cooke JD. Responses to force perturbations preceding voluntary human arm movements. Brain Res. 1981;220(2):350-55. [PMID: 7284760]

113. Cooke JD, Brown S, Forget R, Lamarre Y. Initial agonist burst duration changes with movement amplitude in a deafferented patient. Exp Brain Res. 1985;60(1):184-87. [PMID: 2995107]

114. Cooke JD, Brown SH. Movement-related phasic muscle activation. II. Generation and functional role of the tripha- sic pattern. J Neurophysiol. 1990;63(3):465-72. [PMID: 2329256]

115. Corcos DM, Gottlieb GL, Agarwal GC. Organizing principles for single-joint movements. II. A speed-sensitive strategy. J Neurophysiol. 1989;62(2):358-68. [PMID: 2769335]

116. Ghez C, Gordon J. Trajectory control in targeted force impulses. I. Role of opposing muscles. Exp Brain Res. 1987;67(2):225-40. [PMID: 3622686]

117. Marzke MW, Toth N, Schick K, Reece S, Steinberg B, Hunt K, Linscheid RL, An KN. EMG study of hand muscle recruitment during hard hammer percussion manufacture of Oldowan tools. Am J Phys Anthropol. 1998; 105(3):315-32. [PMID: 9545075]

118. Haaland KY, Harrington DL. Limb-sequencing deficits after left but not right hemisphere damage. Brain Cogn. 1994;24(1):104-22. [PMID: 7772095] Erratum in: Brain Cogn. 1995;27(1): 134.

119. Prestopnik J, Haaland K, Knight R, Lee R. Hemispheric dominance in the parietal lobe for open and closed loop movements. J Int Neuropsychol Soc. 2003;9:1-2.

Submitted for publication September 1, 2005. Accepted in revised form January 27, 2006. 